\title{
Association of adiponectin level with biochemical variables and insulin resistance in patients with non-alcoholic fatty liver disease in an Iranian population
}

\author{
Mojtaba Rahmani ${ }^{1}$, Masoumeh Nezhadali ${ }^{2}$, Javad Rastegar Moghaddam ${ }^{3}$ \\ ${ }^{1}$ MSc, Department of Biology, Islamshahr Branch, Islamic Azad University, Islamshahr, Iran \\ ${ }^{2}$ Department of Biology, Islamshahr Branch, Islamic Azad University, Islamshahr, Iran \\ ${ }^{3}$ Faculty of Medicine, Tehran Medical Branch, Islamic Azad University, Tehran, Iran
}

\begin{abstract}
Background: Non-alcoholic fatty liver disease is one of the most important chronic liver disorders worldwide. Adipokines are polypeptide hormones that participate in the pathogenesis of non-alcoholic fatty liver disease. Adiponectin is an adipokine that stimulates fatty acid oxidation in muscle and plays a role in the development of insulin sensitivity. This study aimed to investigate the association between plasma adiponectin and nonalcoholic fatty liver disease.

Materials and methods: This case and control study was conducted on 80 non-alcoholic fatty liver disease patients and 80 participants as control group. Plasma levels of adiponectin and insulin were measured by ELISA kit (Mercodia Company, Sweden) and other variables were determined by standard methods. Statistical analysis was performed using SPSS software, version 19.

Results: Plasma adiponectin was significantly lower in non-alcoholic fatty liver disease patients than control (p-value<0.001). Whereas, subjects with non-alcoholic fatty liver disease had significantly higher levels of body mass index, serum transaminases, serum triglycerides, systolic blood pressure, serum insulin and insulin resistance compared to control group $(\mathrm{p}<0.01)$. An inverse correlation was observed between adiponectin with serum transaminases, triglycerides and insulin resistance $(\mathrm{P}<0.05)$, while it did not correlate with lipoproteins.

Conclusion: The results indicate that adiponectin levels are reduced in individuals with non-alcoholic fatty liver disease. Adiponectin levels are inversely correlated with liver transaminases and insulin resistance. Keywords: Adiponectin, Insulin resistance, Fatty liver, Lipoprotein.

Cited as: Rahmani M, Nezhadali M, Rastegar Moghaddam J. Association of adiponectin level with biochemical variables and insulin resistance in patients with non-alcoholic fatty liver disease in an Iranian population. Medical Science Journal of Islamic Azad University, Tehran Medical Branch 2019; 29(4): 329-336.
\end{abstract}

Correspondence to: Masoumeh Nezhadali

Tel: +989123875493

E-mail: ma_nejadali@yahoo.com

ORCID ID: 0000-0002-3931-9807

Received: 13 Jun 2019; Accepted: 16 Apr 2019 
مجله علوم :زشكى دانشگاه آزاد اسلامى

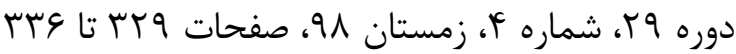

\title{
ارتباط سطح آدييونكتين با متغيرهاى بيوشيميايى و مقاومت به انسولين در بيماران مبتلا به كبد جرب غير الكلى در يك جمعيت ايرانى
}

\author{
مجتبى رحمانى'، معصومه نزادعلى'، جواد رستخار مقدمّ
}

$$
\begin{aligned}
& \text { ' كارشناس /رشد، كروه زيست شناسى، واحد /سلامشهر، دانشكاه آزاد /سلامى، اسلامشهر، ايران }
\end{aligned}
$$

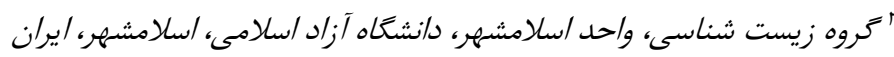

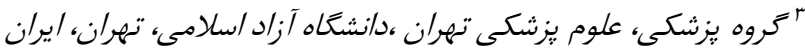

سابقه و هدف: بيمارى كبد جرب غير الكلى يكى از مهمترين اختلالات مزمن كبدى در جهان است. آديبوكينها هورمونهاى يلى

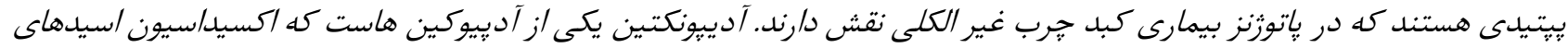

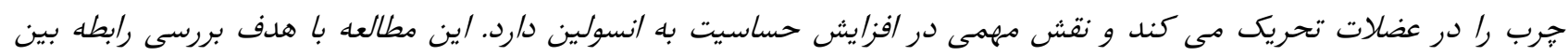

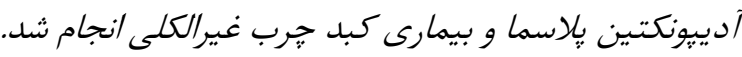

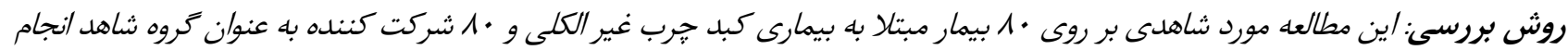

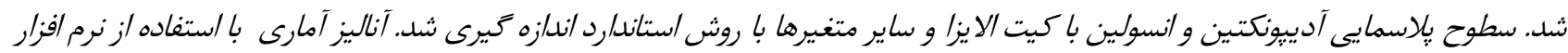
SPSS

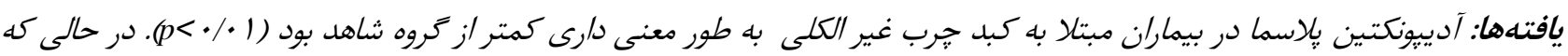

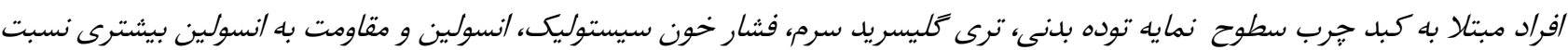

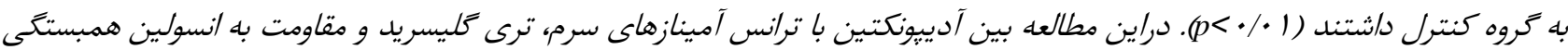

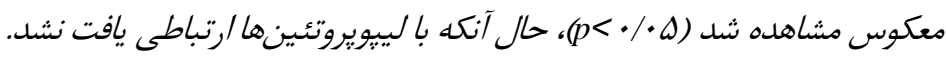

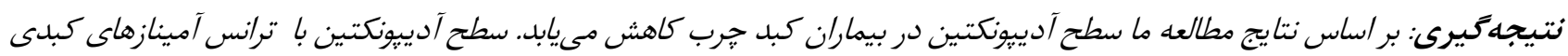
و مقاومت به انسولين ارتباط معكوس معنى مارىى دارد. وازَان كليدى: آديبونكتين، مقاومت به انسولين، كبل جرب، لييوبروتئين

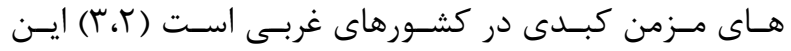

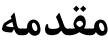

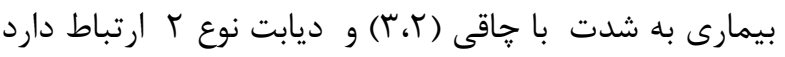

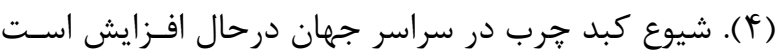

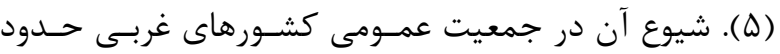

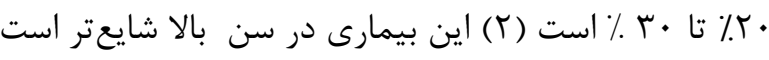

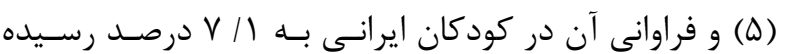

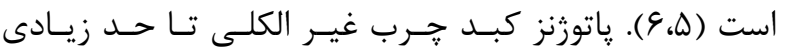

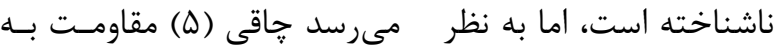

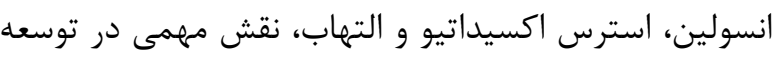

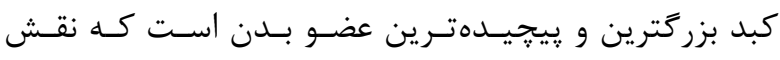

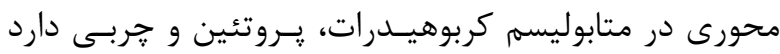
(1). بيمارى كبد جرب غير الكلى يكى از شايعترين بيمارى -
آدرس نويسنده مسئول: اسلامشهر، دانشگاه آزاد اسلامى واحد اسلامشهر، معصومه نزادعلى (email: ma_nejadali@yahoo.com) ORCID ID: 0000-0002-3931-9807

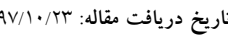

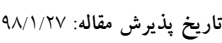




\section{مواد و روشها} يزوهش حاضر به روش مورد-شاهدى انجام شـــ تعـداد افـراد بـر

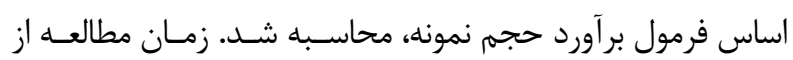

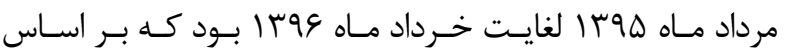

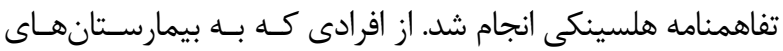

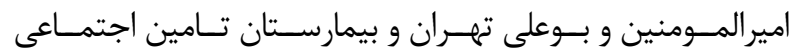

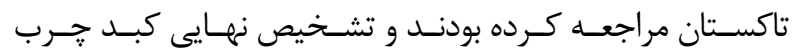

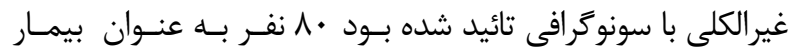

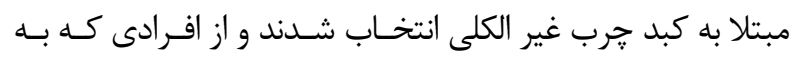

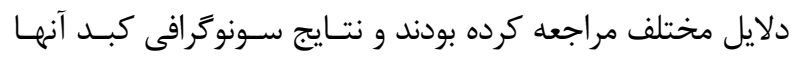

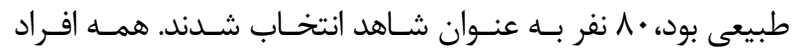

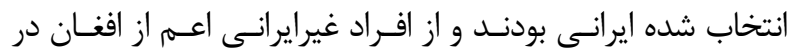

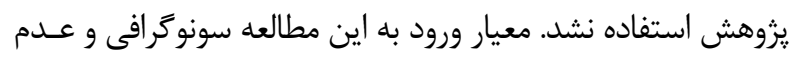

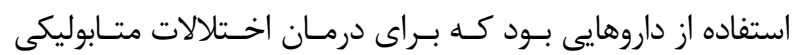

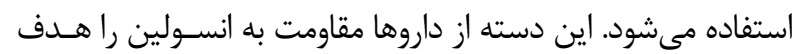

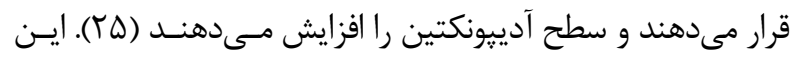

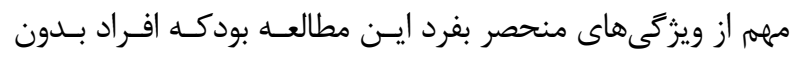

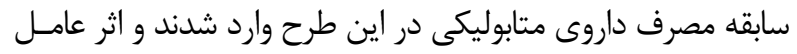
مخدوش كننده دارو حذف شد. معيارهاى خروج از تحقيق سـابقه

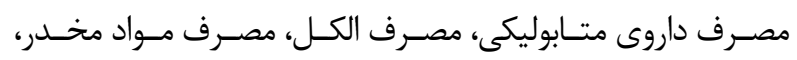

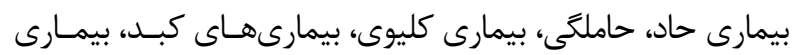

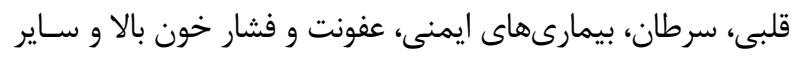

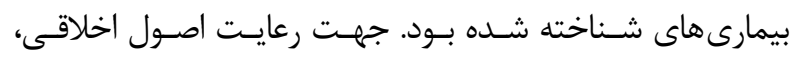

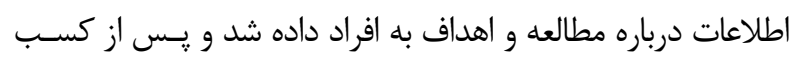

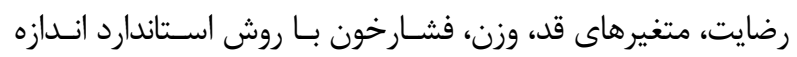

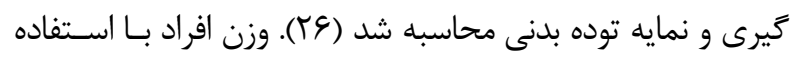

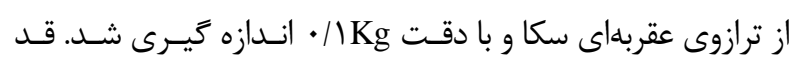

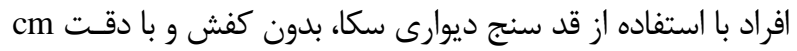

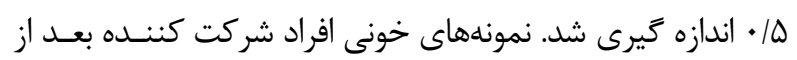

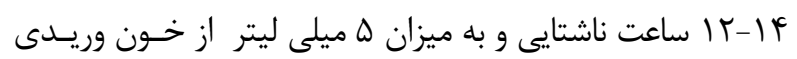
كرفته و در لولههاى فاقد ضد انعقاد جمع آورى شد. همه نمونههـا حداقل مدت نيم ساعت در دماى اتاق نكخهـدارى شــدند تـا ايجـاد

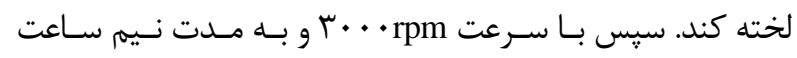

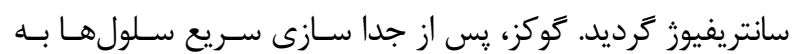
منظور جلوكيرى از كليكوليز، به روش كلوكز اكسيداز و با اسـتفاده

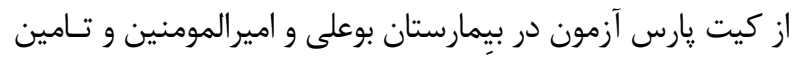

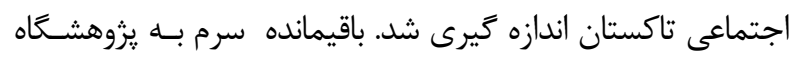
غدد شهيد بهشتى منتقل و در دماى • ^- درجه سانتى كراد نحــهـ

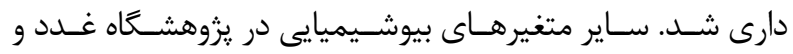

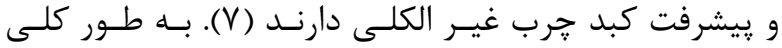
تعامل بسيارى از عوامل محيطى و زينتيكى منجر بـ بـهـ آيويتـوز

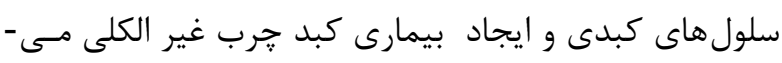

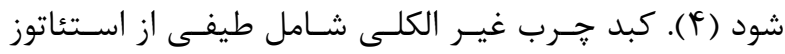

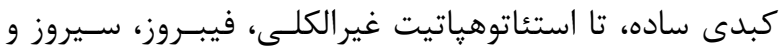

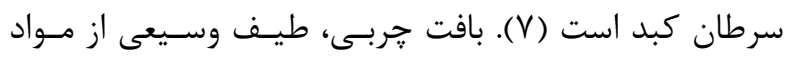

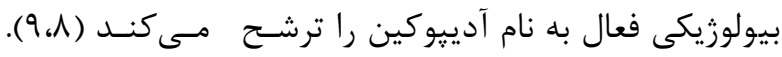

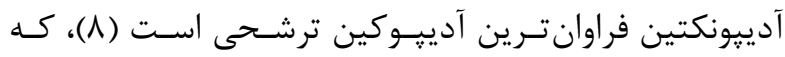

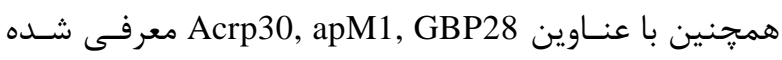

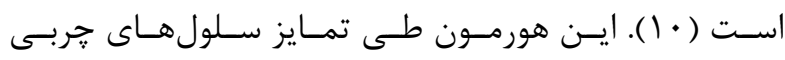

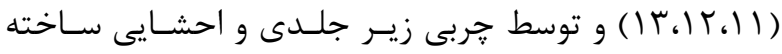

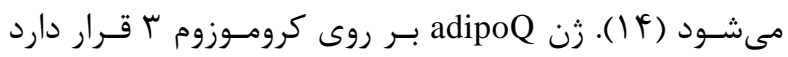

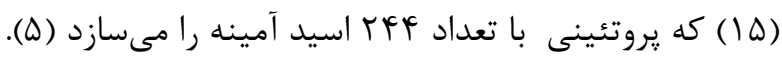

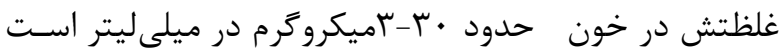

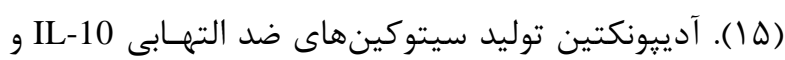

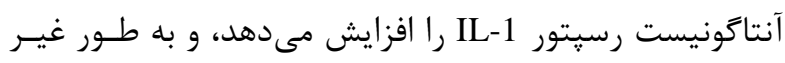
مستقيم توليد سيتوكينهاى التهابى CRP، IL-6 و TNF-

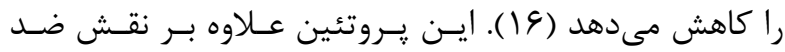

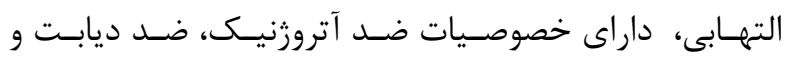

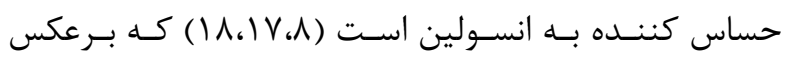

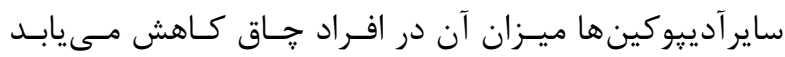

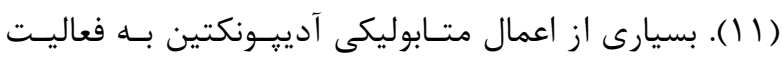

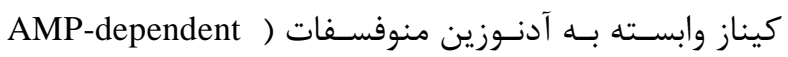

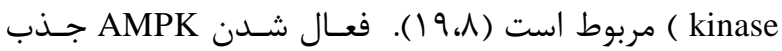

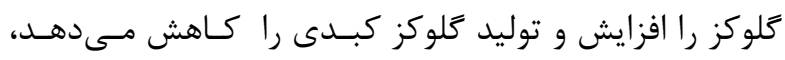

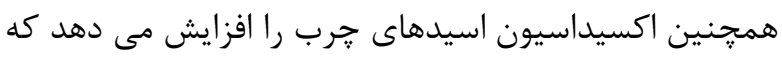

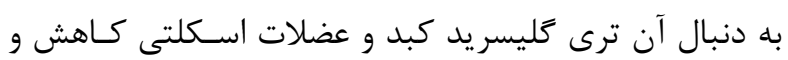

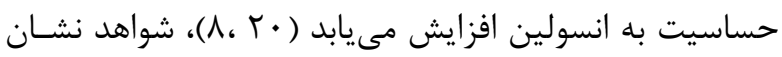

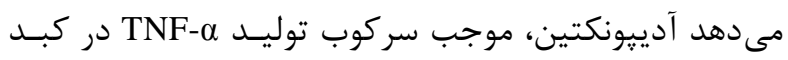

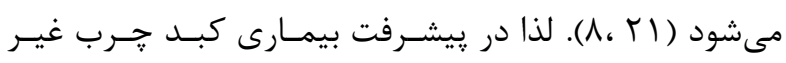

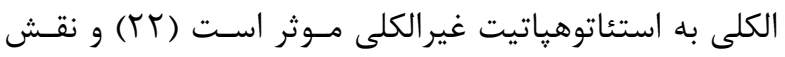

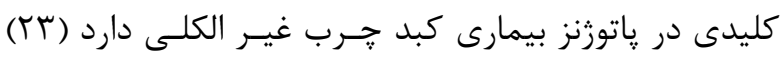

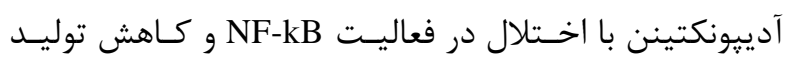
TNF $\alpha$

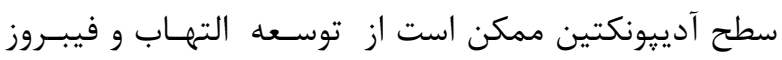

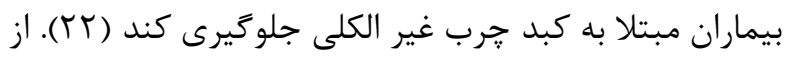

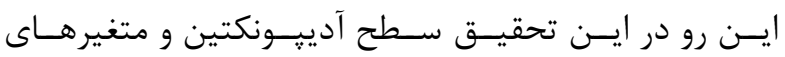

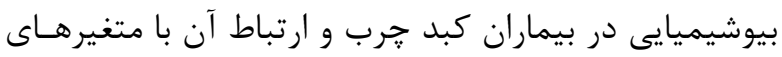
بيوشيميايى تعيين شد. 
نمايه توده بدنى در افراد بيمار بالاتر از افراد سالم بود و

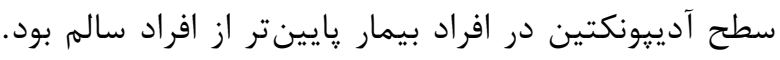
اما در سطح كلسترول، سن، LDL-C و و فشارخون

دياستوليك اختلاف معنى دارى مشاهده نشد ( جدول r). ارتباط آدييونكتين با متغيرهاى بيوشيميايى با استفاده از

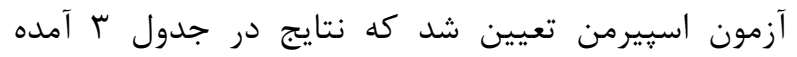

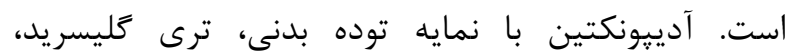
انسولين، مقاومت به انسولين،ALT و AST ارتباط معكوس و معنىىارى داشت (ه •|•>p). اختلاف معنى دار در ساير

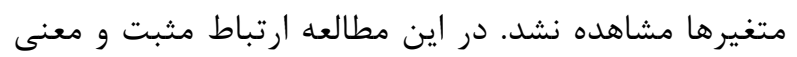
دارى بين مقاومت به انسولين با ترى گليسريد، انسولين، آدييونكتين، ALT و AST مشاهده شد.

جدول ا. نتايج آزمون كولموگروف-اسميرنف جهت بررسى توزيع متغيرهاى مورد مطالعه

\begin{tabular}{|c|c|}
\hline P-value & متغير كمى \\
\hline$\cdot 109$ & سن \\
\hline $.1 . \varepsilon 4$ & نمايه توده بدنى \\
\hline .1 .91 & قند ناشتا \\
\hline$\cdot 19 \Delta \Lambda$ & كلسترول \\
\hline$\cdot / \cdot r$ & ترى گليسريد \\
\hline$\cdot|f|$ & LDL \\
\hline $.1 .9 V$ & HDL \\
\hline$<\cdot 1 \cdot \varphi \Delta$ & AST \\
\hline$\cdot / \cdot 1$ & ALT \\
\hline$<\cdot / \cdot \cdot 1$ & انسولين \\
\hline$<\cdot 1 \cdots 1$ & مقاومت به انسولين \\
\hline$\cdot / \cdot v$ & آدييونكتين \\
\hline$\cdot 1 \cdot \cdot 1$ & فشارخون دياستوليك \\
\hline$\cdot 1 \cdot \cdot 1$ & فشارخون سيستوليك \\
\hline
\end{tabular}

\section{بحث}

در تحقيق حاضر علاوه بر كاهش سطح آدييونكتين در گروه مبتلا به كبد جرب، تفاوت معنىدار در ميزان متغيرهاى

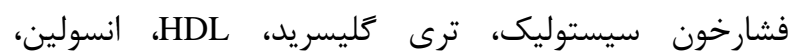
مقاومت به انسولين، نمايه توده بدنى، آنزيمهاى كبدى ALT و AST همجنين ارتباط معنىدارى بين آدييونكتين با نمايه توده بدنى، انسولين، مقاومت به انسولين، ترى گليسريد و آنزيمهاى كبدى يافت شد.
متابوليسم دانشگاه شهيد بهشتى و با كيـتهــاى تجـارى شـركت

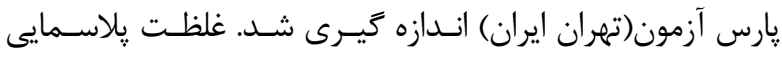

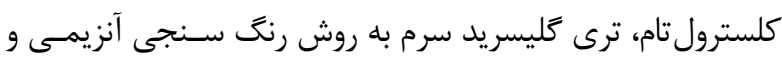

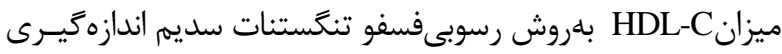

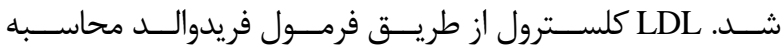

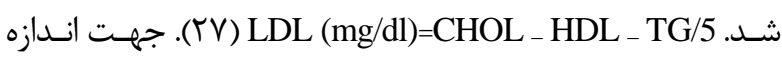
گيــرى آنــزيمم آلانـــين آمينوترانســفراز (ALT) و آســــارتات آمينوترانسفراز (AST) از كيت يارس آزمون و Biotechnica مدل

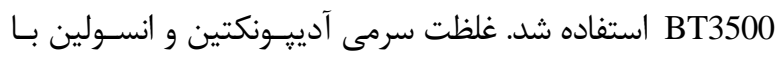

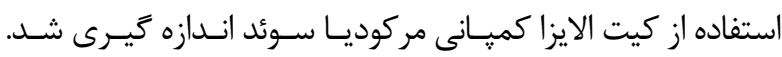

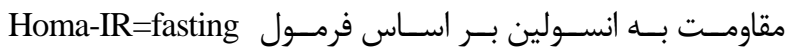
insulin(microU/L)×fasting glucose(nmol/L)/22.5

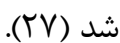

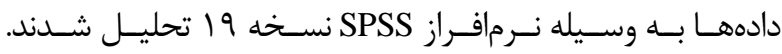

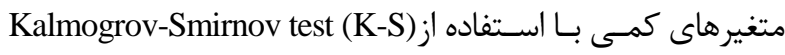
از نظر وضعيت توزيع نرمال بـودن مـورد بررسـى قــرار كرفـت. در

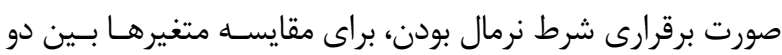

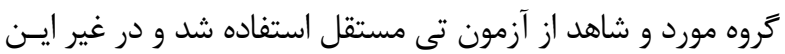

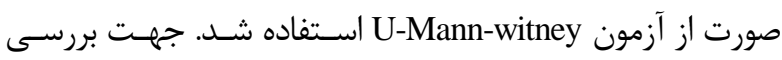

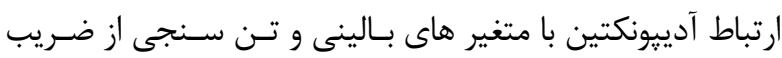
همبستخى اسييرمن استفاده شد. سطح معنى دار آمـارى كمتـر از

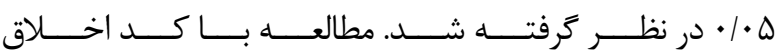
IR.IAU.TMU.REC.1396293 دردانشكده يزشكى دانشـعاه آزاد اسلامى تهران تصويب شد.

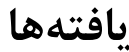

در اين مطالعه ييش از هر گونه تحليلى، توزيع متغيرهاى مورد مطالعه بررسى شد. براى تعيين استفاده صحيح از

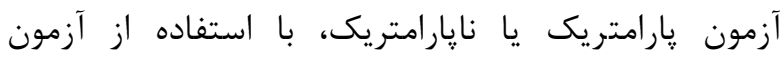
كلموگروف- اسميرنف، نرمال بودن يا غيرنرمال بودن

متغيرهاى مورد مطالعه تعيين شد (جدول (1).

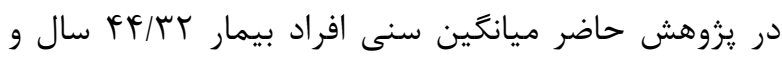

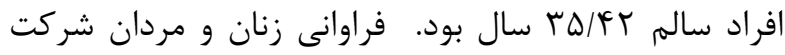

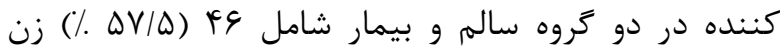

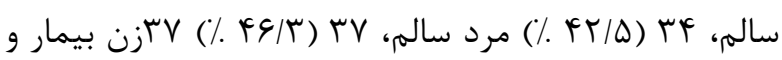

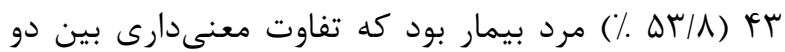

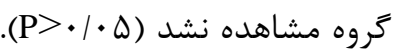
سطح سرمى ترى كليسريد، قند خون ناشتا، انسولين، مقاومت به انسولين، AST ، ALT، فشار خون سيستوليك و 
جدول r. مقايسه متغيرهاى بيوشيميايى و تن سنجى در دو گروه سالم و بيماران مبتلا به كبد جرب غير الكلى

\begin{tabular}{|c|c|c|c|}
\hline P-value & سالم(N=人) & بيمار) • (N=人) & 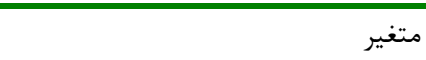 \\
\hline${ }^{*} \mathrm{NS}$ & mF / Fq & er / rv & جنس ( زن/ مرد) \\
\hline$<\cdot / \cdot \cdot 1$ & $r \Delta / \mathcal{F} T \pm N / \Delta$ & $F \psi / r r \pm q / V$ & سن(سال) \\
\hline$<\cdot / \cdot \cdots$ & $r r|q| \pm r / q$ & $r \Lambda / V Y \pm F / G$ & نمايه توده بدنى (كيلوگرم بر متر مربع) \\
\hline NS & $9 r / \cdot \Lambda \pm \Lambda / \cdot r$ & $91 / 9 \wedge \pm 1 r / 1$ & قندخون ناشتا (ميلى گرم بر دسى ليتر) \\
\hline NS & $19 D / T \cdot \pm T r / T r F$ & $I V \cdot / r \cdot \pm F r / r$ & كلسترول (ميلى گرم بر دسى ليتر) \\
\hline$<\cdot / \cdot \cdot 1$ & $q V / \Delta \pm F T / q$ & $\| \Delta / r \cdot \pm F r / r$ & ترى گليسريد (ميلى گرم بر دسى ليتر) \\
\hline NS & $\Lambda 9 / \cdot 9 \pm r r / \Delta$ & $q \varphi / 19 \pm r \cdot / \varepsilon$ & LDL (ميلى گرم بر دسى ليتر) \\
\hline$<\cdot / \cdot \cdot 1$ & FN/FTIIT/I & $r \Delta / / \Delta \pm / r / \varphi$ & HDL(ميلى گرم بر دسى ليتر) \\
\hline$<\cdot 1 \cdot \cdot 1$ & $\mid \varepsilon / \Delta \Delta \pm F / \mathcal{F}$ & $r \varepsilon / 4 Y \pm N / r$ & AST $(\mathrm{IU} / \mathrm{L})$ \\
\hline$<\cdot \mid \cdot \cdot 1$ & $|V / q| \pm V / \Lambda$ & $r \Delta / r \mu \pm I V / r$ & ALT(IU/L ) \\
\hline$<\cdot / \cdot 1$ & $11 / \Delta V \pm \| /{ }^{4}$ & $r T / F \Delta \pm r r$ & انسولين(ميلى مول بر ليتر) \\
\hline$<\cdot 1 \cdot 1$ & $r / 9 \mid \pm r / \Delta$ & $\Delta / \cdot V \pm V / \Gamma$ & مقاومت به انسولين \\
\hline$<\cdot / \cdot \bullet$ & $V / \mathcal{A} \pm \Psi \cdot / \mathcal{F}$ & $\Delta / r \wedge \pm \Gamma \Delta / \varphi$ & آدييونكتين(ميكروگرم بر ميلى ليتر ) \\
\hline NS & $\vee / 9 \Delta \pm \cdot / \pi \Delta$ & $\Lambda / \cdot \pm \cdot / 9 \mathrm{~V}$ & فشار خو ن دياستوليك (ميلى متر جيوه) \\
\hline$<\cdot / \cdot \Delta$ & $11 / 4 \wedge \pm 1 / r$ & $\mid r / T \pm 1 / \Lambda$ & فشارخون سيستوليك (ميلى متر جيوه) \\
\hline
\end{tabular}

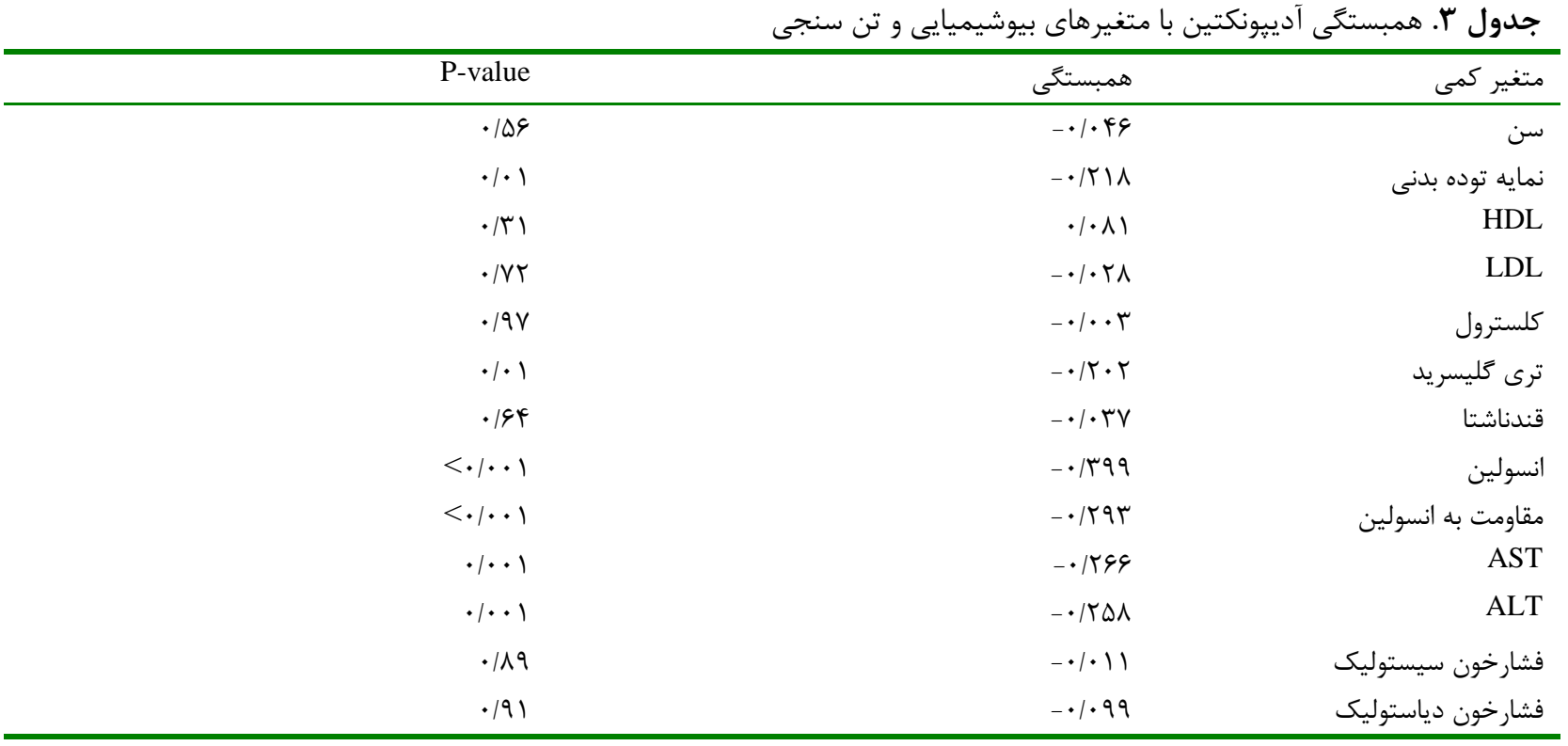

است كه با يِيشرفت كبد جرب غير الكلى ارتباط دارد و به اين

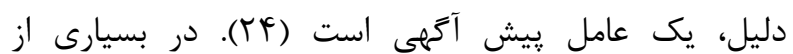

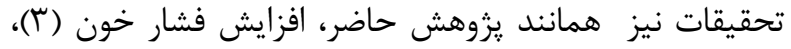
افزايش آنزيمهاى كبدى (T)، ديس ليبيدمى، افزايش سطح

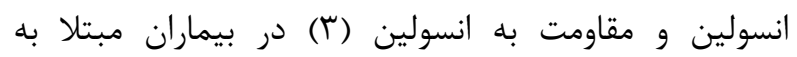
كبدجرب غير الكلى كزارش شده است. اين تغييرات ممكن است به علت كاهش سطح آدييونكتين در بيماران NAFLD

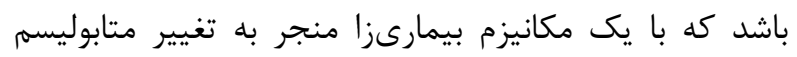

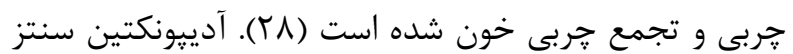
اسيدجرب را با مهار اسيل كوآ كربوكسيلاز (ACC) و كاهش تده
در اين يزوهش مشابه مطالعات ديكر، كاهش و تفاوت معنى

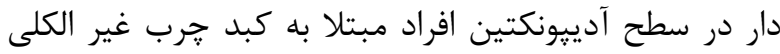

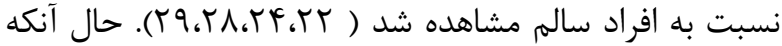
در برخى تحقيقات افزايش سطح آدييونكتين در بيماران

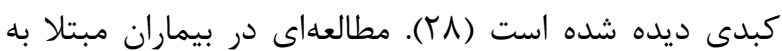

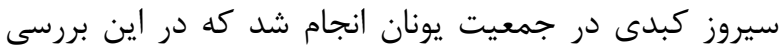
سطح آدييونكتين در بيماران افزايش معنىدارى داشت كه دهان دليل آن اثر حفاظتى آدييونكتين، و واسخ ضد آديون التهابى به آسيب هاى كبدى بيان شد (• آ). در مطالعات انسانى، سطوح يايين آدييونكتين عامل خطر براى NAFLD شناخته شده 
در مطالعه ما سطح آلانين آمينوترانسفراز و آسيارتات ترانس

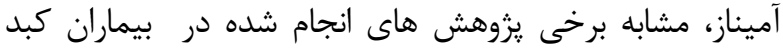

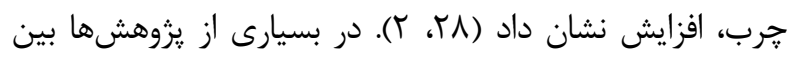

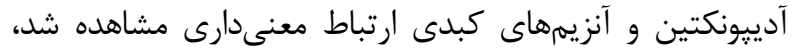
جون آدييونكتين داراى خواص ضد التهابى در كبد است و كمبود

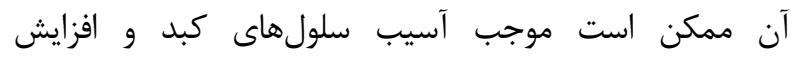
آمينوترانسفرازها و ييشرفت بيمارى كبدى شود (9) ). مطالعات

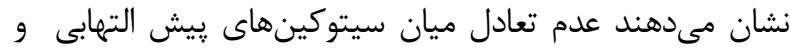

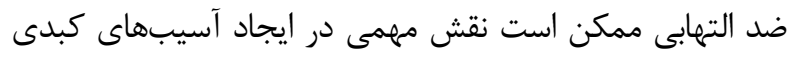

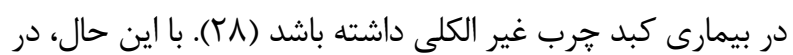

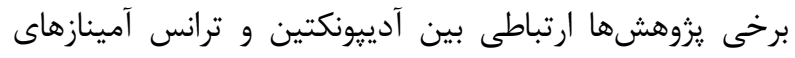

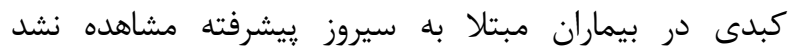

نتايج اين مطالعه نشان مىدهد در جمعيت ما، در بيمارى كبد

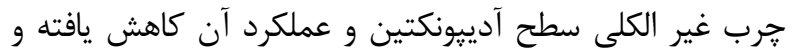

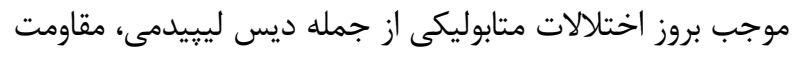

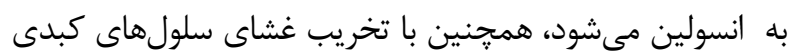

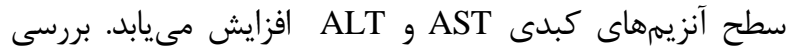

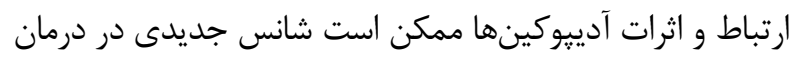

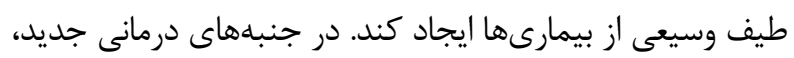
آدييوكينها مى توانند كانديداهاى مطمئنى براى استراتزى درمانهاى دارويى باشند، يا به عنوان ماركر براى تشخيص يا يانيا

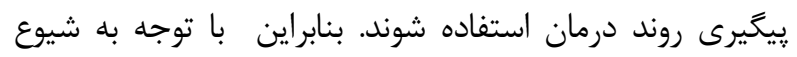

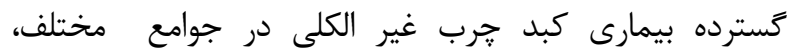
مطالعات بيشتر براى نشان دادن مكانيسمهاى دقيق مبتنى بر برائ

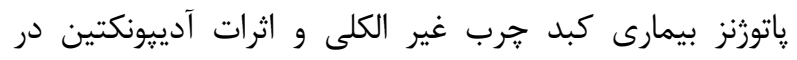
بيشكيرى و درمان ضرورى است. از محدوديتهاى اين مطالعه

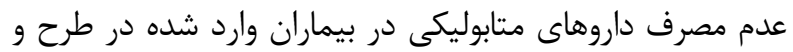
عدم اندازه كيرىهاى سيتوكينهاى ييش التهابى مانند و IL-6 بود كه اثرات آن بر بيمارى كبد جرب ترب اثبات شده است.

\section{تشكر و قدردانى}

بدين وسيله مراتب سياس و قدردانى خود را از خانم دكتر ميترا

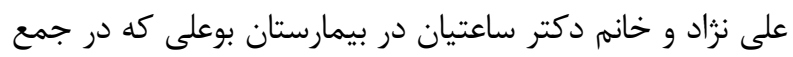

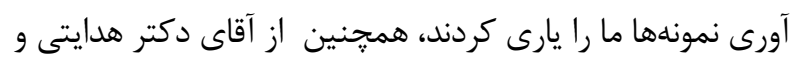
خانم لاله حقوقى و دوستان عزيز در يزوهشكاه غدد دانشكاه

$$
\text { شهيد بهشتى اعلام مى كنيم. }
$$

بيان و فعاليت اسيد خرب سنتاز كاهش مىدهد (ك^)).

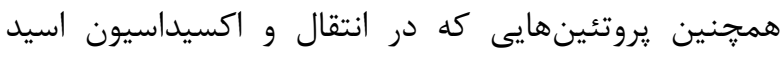

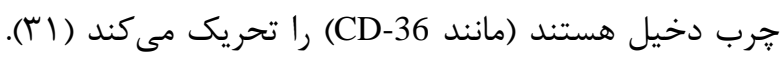

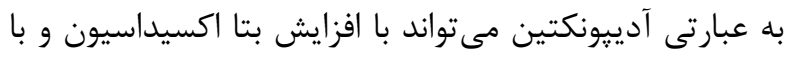
كاهش سنتز اسيد خرب در سلولهاى كبدى از تجمع جربى

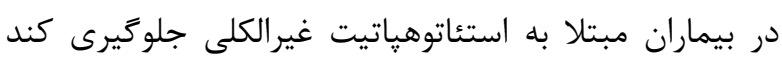

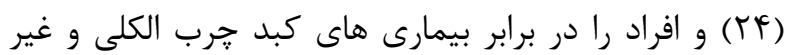

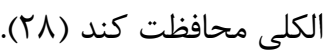

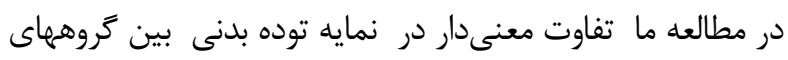

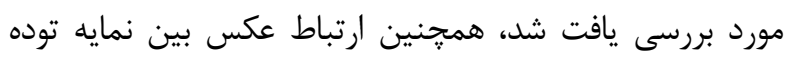
بدنى و سطح آدييونكتين مشاهده شد. آدييونكتين با افزايش

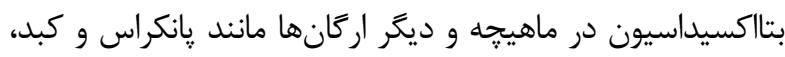

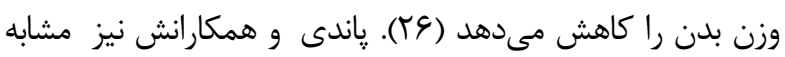

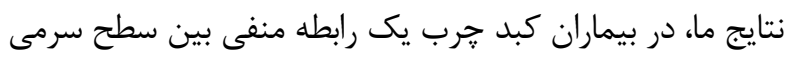

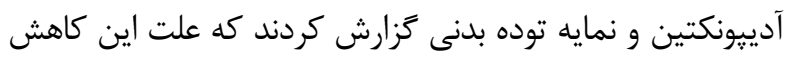

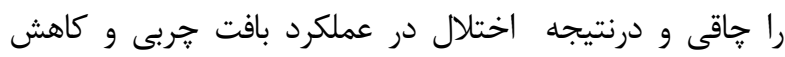

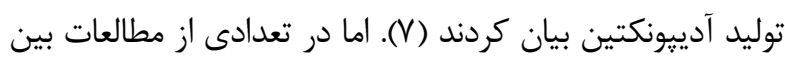

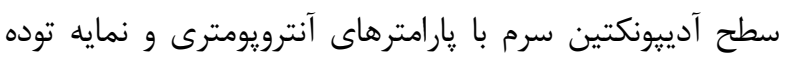

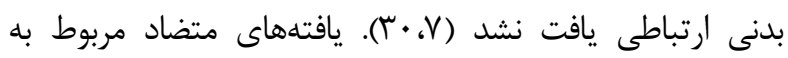
ارتباط بين آدييونكتين و نمايه توده بدنى ارتئ احتمالا در نتيجه تركيب متفاوت گروههاى مورد تحقيق از نظر ميزان اضافه وزن و

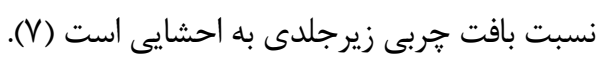

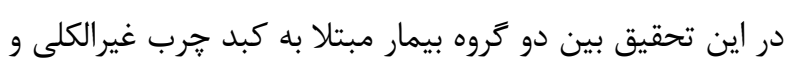

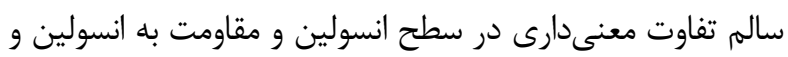

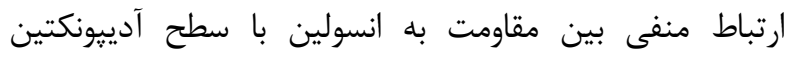

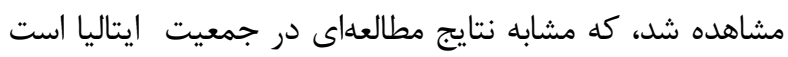

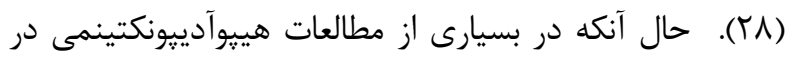

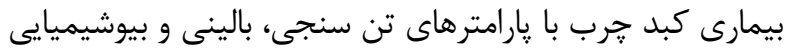

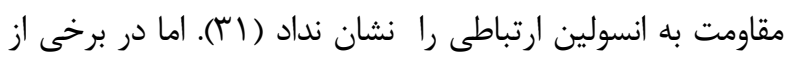

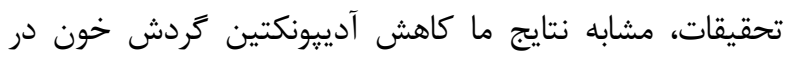

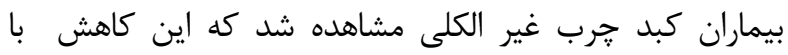

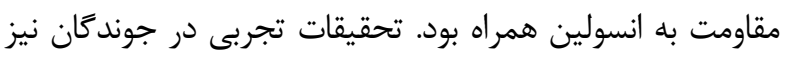

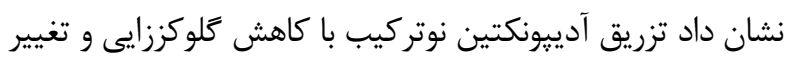
بيان و فعاليت آنزيم هاى كليدى كلوكونوزنز و تحريك

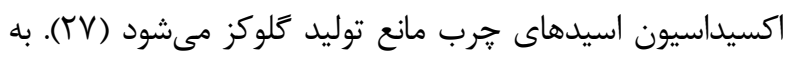

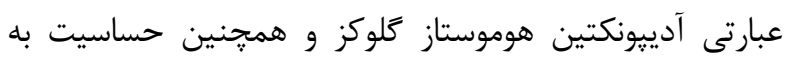

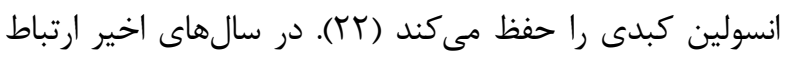

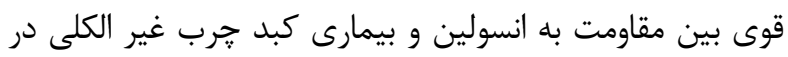

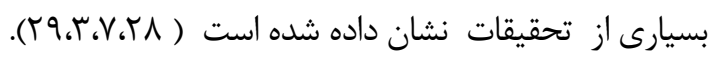


REFERENCES

1. Giannini EG, Testa R, Savarino V. Liver enzyme alteration: a guide for clinicians. CMAJ 2005; 172: 367-79.

2. Lee SS, Park SH. Radiologic evaluation of nonalcoholic fatty liver disease. World J Gastroenterol 2014; 20 : 7392402.

3. Dyson JK, Anstee QM, McPherson S. Non-alcoholic fatty liver disease: a practical approach to treatment. Frontline Gastroenterol 2014; 5: 277-286.

4. Sun C, Fan J-G1, Qiao. L. Potential Epigenetic Mechanism in Non-Alcoholic Fatty Liver Disease. Int J Mol Sci 2015; 16: 5161-5179.

5. Hashemi M, Hanafi Bojd H, Eskandari Nasab E, Bahari A, Hashemzehi NA, Shafieipour S, et al. Association of adiponectin rs1501299and rs266729 Gene Polymorphisms With Nonalcoholic Fatty Liver Disease. Hepat Mon 2013; 13: e9527.

6. Famouri F, Salehi M-M, Rostampour N, Hashemi E, Shahsanaee A. The effect of silymarin on non-alcoholic fatty liver disease of children. J Herbmed Pharmacol 2017; 6: 16-20.

7. Pandey AK, Jalihal U, Pramila MN, Gowda V MN, Vinay MD, Prabhu V. Estimation of adiponectin levels in diabetic, non-diabetic fatty liver diseases and healthy controls International. Int J Res Med Sci 2015; 3: 140-146.

8. Gable DR, Hure SJ, Humphries SE. Adiponectin and its gene variants as risk factors for insuln resistance. Atherosclerosis 2006; 188: 231-44.

9. Carter-Kent C, Zein NN, Feldstein AE. Cytokines in the pathogenesis of fatty liver and disease progression to steatohepatitis: implications for treatment. Am J Gastroenterol 2008; 103:1036-42.

10. Zadjali F, AL-Yahyaee S, Hassan MO, Albarwani S, Bayoum RA. Association of adiponectin promoter variants with traits and clusters of metabolic syndrome in Arab. Gene 2013; 527: 663-9.

11. Ricci R, Bevilacqua F. The potential role of adiponectin in obesity: a comparative review. Vet J 2012; 19: $292-98$.

12. Hsiao T-J, Wu LS, Huang S-Y, Lin E. A common variant in the adiponectin gene on weight loss and body composition under sibutramine therapy in obesity. Clin Pharmacol 2010; 2: 105-110.

13. Sull JW, Kim HJ, Yun JE, KimG. Serum adiponectin is associated with family history of diabetes independently of obesity. Eur J Endocrinol 2009; 160: 39-43.

14. Ronconi V, Turchi F, Rilli S, Di Mattia D. Metabolic syndrome in primary aldosteronism and essential hypertension: relationship to adiponectin gene variants Nutrition. Metabolic Cardiovascular Diseases 2010; 20 : 93-100.

15. Miraoui N, Ezzidi I, Turki A, Chaieb A, et al. Single-nucleotid polymorphisms and haplotypes in the adiponectin gene contribute to the genetic risk for type2 diabetes in Tunisian Arab. Diabetes Res Clin Pract 2012; 97: 290-7.

16. Kiecolt-Glaser JK, Christian LM, Andridge R. Adiponectin, leptin, and yoga practice. Phisyol Behav 2012; 107: 809-13.

17. Arregui M, Fisher E, Kuppel S, Buijsse B. Significant association of the rs2943634(2q36.3 )genetic polymorphism with adiponectin,high density lipoprotein cholesterol and ischemic. Gene 2012; 494: 190-5.

18. Hugo ER, Brandebourg TD, Woo JG, Loftus J, Alexander JW, Ben-Jonathan N. Bisphenol A at environmentally relevant doses inhibits adiponectin release from human adipose tissue explants and adipocytes. Environ Health Perspect 2008;116:1642-7.

19. Hopkins TA, Ouchi N, Shibata R, Walsh K. Adiponectin actions in the cardiovascular system. Cardiovasc Res 2007;74:11-8

20. Minatoya M, KutomiG, AsakuraS, Otokozawa S, Sugiyama Y, Nagata Y, et al. Equol, adiponectin, insulin levels and risk of breast cancer. Asian Pac J Cancer Prev 2013; 14: 2191-99.

21. Kazumi T, Kawaguchi A, Hirano T, Yoshino G. Serum adiponectin is associated with high-density lipoprotein cholesterol, triglycerides, and low-density lipoprotein particle size in young healthy men. Metabolism 2004; 53: 589-93.

23. Du S-X, Lu LL, Liu Y, Dong QJ, Xuan SY, Xin YN. Association of adiponectin gene polymorphisms with the risk of coronary artery disease in patients. Hepat Mon 2016; 16: e37388.

24. Marino L, Jornayvaz FR Endocrine causes of nonalcoholic fatty liver disease. World J Gastroenterol 2015; 21: 11053-76.

25. Polyzos SA, Mantzoros CS. Adiponectin as a target for the treatment of nonalcoholic steatohepatitis with thiazolidinediones: a systematic review. Metabolism 2016; 65: 1297-1306. 
26. Gonzalez-Castejon, D, Rodriguez-Casado A. Dietary phytochemicals and their potential effects on obesity: a review. Pharmacol Res 2011; 64: 438-55.

27. Prakash J, Mittal B, Awasthi S, Srivastava N. Association of adiponectin gene polymorphism with adiponectin levels and risk for insulin resistance syndrome. Int J Prev Med 2015; 6:31.

28. Pagano C, Soardo G, Esposito W, Francesco Fallo F Basanl, Donnini D. Plasma adiponectin is decreased in nonalcoholic fatty liver disease. Eur Endocrinol 2005; 152:113-8.

29. Bugianesi E, Pagotto U, Manini R, Vanni E, Gastaldelli A, De Iasio R, et al. Plasma adiponectin in nonalcoholic fatty liver is related to hepatic insulin resistance and hepatic fat content, not to liver disease severity. J Clin Endocrinol Metab 2005; 90: 3498-504.

30. Kalafateli M, Triantos, C, Tsochatzis, E, Michalaki, M, Koutroumpakis E, Thomopoulos K, et al. Adipokines levels are associated with the severity of liver disease in patients with alcoholic cirrhosis. World J Gastroenterol 2015; 21: 3020-29.

31. Esfahani M, Movahedian A, Baranchi M, Goodarzi MT. Adiponectin: an adipokine with protective features against metabolic syndrome. Iran J Basic Med Sci 2015; 18: 430-42. 